\title{
Mesangial Cell
}

National Cancer Institute

\section{Source}

National Cancer Institute. Mesangial Cell. NCI Thesaurus. Code C13159.

Cell found within the glomerular lobules of mammalian kidney. Mesangial cells serve as structural supports, may regulate blood flow, are phagocytic and may act as accessory cells, presenting antigen in immune responses. 